\title{
Spontaneous Capillary Imbibition of Water and Nonaqueous Liquids into Dry Quarry Limestones
}

\author{
Christopher Hall $^{1}$ (D) . Victoria Pugsley ${ }^{1}$
}

Received: 9 August 2020 / Accepted: 9 October 2020 / Published online: 2 November 2020

(c) The Author(s) 2020

\begin{abstract}
Rates of spontaneous imbibition of water and nonaqueous liquids into dry limestones have been measured at $25{ }^{\circ} \mathrm{C}$. Thirteen English and French limestones were used, with eight liquids (water, decane, dodecane, sec-butanol, iso-propanol, tetrahydrofuran, perfluorodimethylcyclohexane, ethanediol). For the nonaqueous liquids, the measured sorptivity generally scales as (surface-tension/viscosity) ${ }^{1 / 2}$ (here called $F$-scaling). Water sorptivities deviate from $F$-scaling, indicating partial wetting. A wetting coefficient (wetting index) is derived. Data show that there is little difference in the Hirschwald saturation coefficient measured with the different liquids, although there is a large variation between stones. Results suggest that physicochemical alteration of exposed pore surfaces strongly (and unpredictably) influences the capillary absorption of water by limestones.
\end{abstract}

Keywords Imbibition · Hirschwald coefficient $\cdot$ Limestones $\cdot$ Sorptivity $\cdot$ Wettability Wetting coefficient

\section{Introduction}

In this paper, we report and discuss some results from two series of experiments on the spontaneous imbibition of liquids by capillary rise in small blocks of quarry limestones. These experiments were designed to explore the short-term primary imbibition that is driven by Lucas-Washburn capillarity, in particular how the sorptivity $S$ which describes the kinetics of imbibition depends on the surface tension $\sigma_{\ell}$ and viscosity $\eta_{\ell}$ of the imbibed liquid. Earlier work (Taylor 1998; Taylor et al. 2000) had shown that water imbibition in some limestones is slower than expected from a simple $\left(\sigma_{\ell} / \eta_{\ell}\right)^{1 / 2}$ scaling, pointing to partial (or incomplete) wetting by water in these materials. But the results reported here are more extensive: more stones and more liquids.

Many of these experiments were of long duration, carried out to investigate not only the primary imbibition but also the long-term secondary imbibition that is controlled by the slow diffusion of air trapped in the primary process. While the timescale of the primary imbibition on small blocks is rarely more than a day, the secondary process may

Christopher Hall

christopher.hall@ed.ac.uk

1 School of Engineering, University of Edinburgh, Edinburgh EH9 3JL, UK 
last several years. Some observations of the long-term secondary imbibition of water are described elsewhere (Hall and Hamilton 2018). This paper deals only with the primary process, while the long-term imbibition of nonaqueous liquids will be the subject of another publication.

Materials in context Limestones have been widely used as materials of construction for many centuries, on all inhabited continents, and in all building types. Durability is a requirement and a preoccupation in specification, maintenance and conservation. Deterioration and decay is largely mediated by water. Spontaneous capillary imbibition is the main way by which water enters stone materials in the building fabric. Capillary processes control also both the internal migration of water and evaporative drying (Hall and Hoff 2007). Our understanding of capillarity in limestones, including the fundamentals of wetting, remains incomplete, hence this study.

\section{Materials and Methods}

Two series of tests were carried out. In Series One, nine limestones were used, with water, $n$-decane, $n$-dodecane and butan-2-ol (sec-butyl alcohol) as imbibition liquids. In Series Two, four limestones were used, with water, $n$-dodecane, propan-2-ol (iso-propyl alcohol), tetrahydrofuran, ethane-1,2-diol (ethylene glycol) and perfluoro-1,3-dimethylcyclohexane as imbibition liquids. All tests were carried out at $25^{\circ} \mathrm{C}$. The Series Two limestones were from the same geological formations as the English limestones of Series One. However, the corresponding stones were from different locations, had different petrophysical properties and should be regarded as distinct materials.

Limestones The Series One limestones, five French and four English, are listed in Table 1. Materials were specimen blocks of freshly quarried limestones, supplied by Rattee and Kett, Cambridge, UK. The physical properties of these nine stone types have been discussed in Hall and Hamilton (2016). All nine are known to be calcitic limestones, as is apparent from the measured solid densities which in every case are close to the crystallographic density of pure calcite, $2709 \mathrm{~kg} / \mathrm{m}^{3}$. Imbibition tests were carried out on rectangular blocks of cross section $50 \times 50 \mathrm{~mm}$ and approximately $100 \mathrm{~mm}$ in length.

The Series Two materials were the four English limestones identified in Table 1, also freshly quarried, and supplied by Fairhaven Stone, Bottisham, Cambridge, UK. These four materials are also known to be calcitic limestones with no more than trace amounts of other minerals, and were used in the form of $50 \times 50 \times 50 \mathrm{~mm}$ cubes.

Imbibition liquids These are listed in Table 2, with values of the relevant physical properties. All nonaqueous liquids were of chemical reagent-grade purity and used as received without further treatment. Water was distilled or deionised. None of the liquids was deaired before use. The liquid fluorocarbon in Series Two was used primarily because of its high Henry constant for air solubility, but here it is of special interest because of its exceptionally low surface tension. It was supplied as Flutec PP3 by F2 Chemicals, Preston, UK.

Imbibition measurements In both Series, we followed the procedure to determine the sorptivity originally described in Hall and Tse (1986), except that in Series Two tests were carried out in closed boxes to prevent evaporation. Imbibition is through one face of the block in contact with liquid. This widely used arrangement establishes one-dimensional co-current capillary flow with a constant-concentration boundary condition at the inflow surface. The other five faces are open to the atmosphere. In all cases, the temperature was controlled to within $\pm 0.5^{\circ} \mathrm{C}$ of the setpoint temperature or better. Weights were measured 
Table 1 Types and properties of limestone materials

\begin{tabular}{llll}
\hline Type & $\begin{array}{l}\text { Bulk density } \rho_{b} \\
\mathrm{~kg} / \mathrm{m}^{3}\end{array}$ & $\begin{array}{l}\text { Solid density } \rho_{s} \\
\mathrm{~kg} / \mathrm{m}^{3}\end{array}$ & Porosity $f[-]$ \\
\hline Series One & & & \\
Ancaster An1 & 2190 & 2710 & 0.194 \\
Bath Ba1 & 2060 & 2710 & 0.242 \\
Chauvigny Ch & 2350 & 2700 & 0.132 \\
Clipsham C11 & 2230 & 2720 & 0.181 \\
Euville Eu & 2320 & 2710 & 0.143 \\
Massangis Ma & 2320 & 2700 & 0.141 \\
Portland Po1 & 2050 & 2700 & 0.241 \\
Richemont Ri & 1940 & 2700 & 0.281 \\
Savonnières Sa & 1690 & 2700 & 0.374 \\
Series Two & & & \\
Ancaster An2 & 2300 & 2710 & 0.153 \\
Bath Ba2 & 2050 & 2720 & 0.245 \\
Clipsham C12 & 2140 & 2720 & 0.212 \\
Portland Po2 & 2130 & 2710 & 0.212 \\
\hline
\end{tabular}

(1) Physical properties were measured by vacuum saturation and Archimedes buoyancy methods (Hall and Hamilton 2015, 2016), except Euville where porosity and bulk density were measured by mercury intrusion porosimetry, assuming solid density $2710 \mathrm{~kg} \mathrm{~m}^{-3}$. (2) Densities, porosities rounded to 3 significant figures. (3) Stone sources and descriptions: Massangis jaune clair; Ba1 Monk's Park, Ba2 Hartham Park, both from the Bath limestone formation; Ancaster An2 hard white; Portland Po2 base bed

Table 2 Imbibition liquids and their physical properties at $25^{\circ} \mathrm{C}$

\begin{tabular}{llllc}
\hline Liquid & Density $\rho_{\ell} \mathrm{kg} / \mathrm{m}^{3}$ & $\begin{array}{l}\text { Surface tension } \sigma_{\ell} \\
\mathrm{mN} / \mathrm{m}\end{array}$ & Viscosity $\eta_{\ell} \mathrm{mPa} \mathrm{s}$ & $\begin{array}{l}F \\
\left(\sigma_{\ell} / \eta_{\ell}\right)^{1 / 2} \\
(\mathrm{~m} / \mathrm{s})^{1 / 2}\end{array}$ \\
\hline $\begin{array}{l}\text { Water } \\
\begin{array}{l}\text { Series } \text { One } \\
\text { Butan-2-ol }\end{array}\end{array}$ & 997 & 72.0 & 0.890 & 8.992 \\
$n$-Decane & 805 & 22.6 & 3.248 & 2.636 \\
$n$-Dodecane & 728 & 23.4 & 0.863 & 5.207 \\
$\begin{array}{l}\text { Series Two } \\
n \text {-Dodecane }\end{array}$ & 745 & 24.9 & 1.390 & 4.233 \\
$\begin{array}{l}\text { Ethane-1,2-diol } \\
\begin{array}{l}\text { Perfluoro-1,3-di- } \\
\text { methylcyclohexane }\end{array}\end{array}$ & 1110 & & & 1.707 \\
$\begin{array}{l}\text { Propan-2-ol } \\
\text { Tetrahydrofuran }\end{array}$ & 1828 & 48.4 & 16.61 & 2.941 \\
\hline
\end{tabular}

Values from (Yaws and Lan 2009; Yaws and Pike 2009; Yaws and Richmond 2009), except water (Hall and Hoff 2012), perfluorodimethylcyclohexane for which data were supplied by F2 Chemicals, densities of propan-2-ol (Martín Contreras 2001) and tetrahydrofuran (Chen et al. 2015), and viscosity of ethane-1,2diol (Quijada-Maldonado et al. 2013) 
on balances reading to $0.01 \mathrm{~g}$. Sample weights were in the range of 400-550 g in Series One and 250-300 g in Series Two. The sorptivity was obtained as the slope at early times. Tests reported here generally showed excellent linearity of $i\left(t^{1 / 2}\right)$ in primary imbibition (Fig. 1). The tests in Series One were designed solely to measure the sorptivity and generally were ended after about three hours. In Series Two, the tests were of longer duration, and measurements were taken for a minimum of 1-2 days to allow both the sorptivity and the Hirschwald coefficient to be determined.

\section{Capillary Imbibition}

We assume, as a working hypothesis, that the observed imbibition is a pure capillarity process. Imbibition through a single face of area $A$ of a rectangular block increases as $t^{1 / 2}$ where $t$ is the elapsed time (Hall and Hoff 2012), so that the cumulative imbibed volume per unit face area $i=B+S t^{1 / 2}$, where $S$ is the sorptivity. $B$ is a constant to account for (small) early-time effects due primarily to the filling of surface pores. The quantity $i$ has dimension $[\mathrm{L}]$ and is reported here in unit mm. The quantity $S$ (dimension [ $\mathrm{L} \mathrm{T}^{-1 / 2}$ ], and unit $\mathrm{mm} / \mathrm{min}^{1 / 2}$ ) is a property of the porous material, the value of which depends also on the imbibition liquid and the temperature. In Sharp Front models, $S=\left(2 \theta_{\ell} K_{e} \Psi_{f}\right)^{1 / 2}$, where $\theta_{\ell}$ is the volume-fraction liquid content of the wetted region, $K_{e}$ is the (effective) permeability of the wetted region (dimension $\left[\mathrm{L} \mathrm{T}^{-1}\right]$ ), and $\Psi_{f}$ is the capillary potential at the wet front (dimension [L]). All of these quantities are assumed to remain unchanged throughout the imbibition process. The liquid content $\theta_{\ell}$ is somewhat less than the volume-fraction open porosity $f$ since air is trapped during imbibition; that is, to say, in petrophysical terminology $1-\theta_{\ell} / f$ is the residual nonwetting phase saturation. Alternatively stated, the quantity $\theta_{\ell} / f=\mathrm{H} / 100$ where $\mathrm{H}$ is the Hirschwald saturation coefficient (Hirschwald 1912; Zinszner and Pellerin 2007). Accordingly, the effective permeability $K_{e}$ is the hydraulic conductivity of the wetted region at liquid content $\theta_{\ell}$.

For different liquids $\ell, K_{e}$ varies as $[\sim] \rho_{\ell} / \eta_{\ell}$, and for complete wetting $\Psi_{f} \sim \sigma_{\ell} / \rho_{\ell}$, where $\rho_{\ell}$ is the liquid density. It then follows that the sorptivity $S \sim\left(\sigma_{\ell} / \eta_{\ell}\right)^{1 / 2}$. (Here we

Fig. 1 Cumulative imbibition $i$ vs $t^{1 / 2}$. a Series One, water imbibition into Richemont limestone, $S 0.980 \pm 0.006 \mathrm{~mm} \mathrm{~min}^{-1 / 2}$ (uncertainty is standard error of regression estimate); $\mathbf{b}$ Series Two, perfluorodimethylcyclohexane imbibition into Clipsham limestone, $S$ $0.202 \pm 0.001 \mathrm{~mm} \mathrm{~min}^{-1 / 2}$. In (b) the Hirschwald coefficient is obtained as the intersection of the straight-line fits to the primary and secondary portions of the data
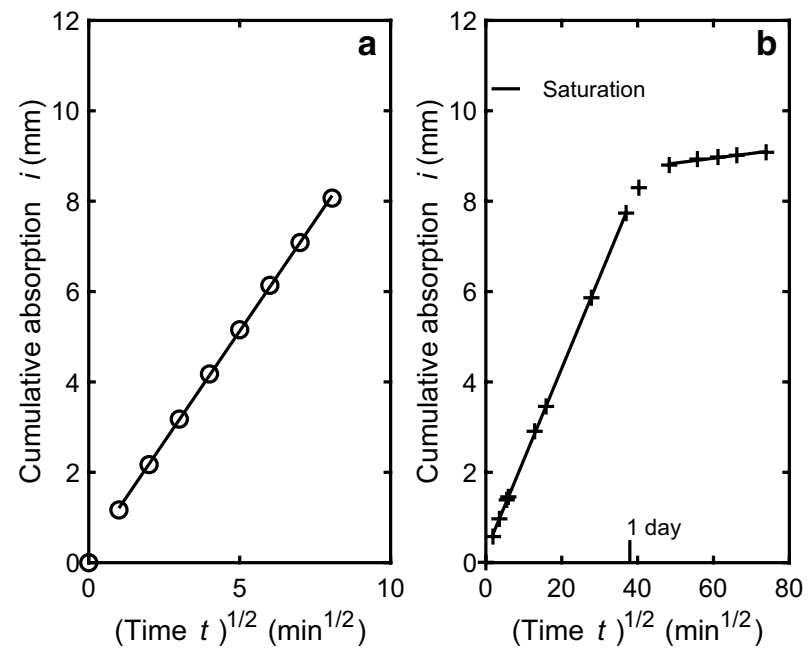
use the Sharp Front model heuristically in order to show the scaling, but the same scaling is implicit in unsaturated flow, Buckingham-Richards and extended Darcy models (as Hall and Hoff 2012, for example). This scaling is expected to account also for the temperature variation of $S$, which to a good approximation it does (Ioannou et al. 2017). If the solid-liquid capillary interaction is one of partial wetting, then we may introduce a wetting coefficient $\beta$ such that $\Psi_{f} \sim \beta \sigma_{\ell} / \rho_{\ell}$. The quantity $\beta$ is formally equivalent to $\cos \gamma$ where $\gamma$ is a notional contact angle. In earlier publications (Taylor et al. 2000; Hall and Hoff 2012), we have called $\beta$ the wetting index, but here we revert to the term wetting coefficient used elsewhere (Somorjai 1970; Rowlinson and Widom 1982).

Denoting the quantity $\left(\sigma_{\ell} / \eta_{\ell}\right)^{1 / 2}$ by $F$, as in (Ioannou et al. 2017), then for any porous material $S_{\ell} / F_{\ell}=\mathbb{S}$ is the same for all completely wetting liquids. The quantity $\mathbb{S}$ is the intrinsic sorptivity (dimension $\left[\mathrm{L}^{1 / 2}\right]$ ), independent of the properties of the liquid. It is also useful to normalise the sorptivity by the sorptivity $S_{1}$ of a reference liquid 1 , so that $S_{\ell} / S_{1}=F_{\ell} / F_{1}$. This relation applies to the complete wetting of any porous material, and since $F_{\ell} / F_{1}$ depends only on liquid properties, it represents a master line for the sorptivity of different materials with different complete-wetting liquids. Any deviations from this are an indication of partial wetting, and a value of wetting coefficient $\beta<1$ can be calculated as $\beta=\left[S_{\ell} F_{1} /\left(S_{1} F_{\ell}\right)\right]^{2}$.

Scientific background This paper has measurements of sorptivity as its primary data and uses for this fundamental imbibition property the unsaturated-flow theory developed in soil physics by Klute (1952), Philip (1957a, (1969) and others. The sorptivity is rigorously defined in relation to nonlinear flow equations (Philip 1957b). This theory is now widely used also in building physics (Hall 1977; Gummerson et al. 1980; Hall 1989). Cumulative imbibition is routinely measured in 1-D co-current capillary-rise tests in which air is freely displaced. Imbibition is expected and found to follow $\sqrt{ }$ (time) kinetics (Green and Ampt 1911; Philip 1957a). Image-based water-content distributions during imbibition have repeatedly been shown to be self-similar, and from these water diffusivity (dispersivity) functions are derived: Gummerson et al. 1979; Carmeliet et al. 2004; Schmid et al. 2016, for example. In brick, stone and concrete, capillary forces are relatively strong, and gravitational effects often negligible (Bond number $\ll 1$ ). Analysis of imbibition in petrophysics, for example (Schmid and Geiger 2012), uses a similar nonlinear continuum formalism, although emphasising the flow of immiscible liquids. Capillary displacement of air by water during spontaneous imbibition in stable porous materials is largely settled science. The main open questions are about air trapping, long-term air diffusion and wetting phenomena. Here, we test the $(\sigma / \eta)^{1 / 2}$ scaling ( $F$-scaling) of the sorptivity property for one important group of materials. This scaling was noted by Washburn (1921) and used in Eley and Pepper (1946), but first stated in direct relation to unsaturated flow by Philip (1957b), who defined the intrinsic sorptivity by means of it and included a contact angle. This scaling accounts for the temperature dependence of the sorptivity (Gummerson et al. 1980; Ioannou et al. 2017).

\section{Imbibition Behaviour: Results and Discussion}

Series One This comprises 69 individual imbibition tests, and the results are assembled in Fig. 2. Decane is used as the reference liquid. Sorptivity values estimated from butan-2-ol and dodecane imbibition tests lie on or close to the decane-referenced master line, showing that for these liquids the $F$-scaling holds. All the water sorptivity values lie well below 


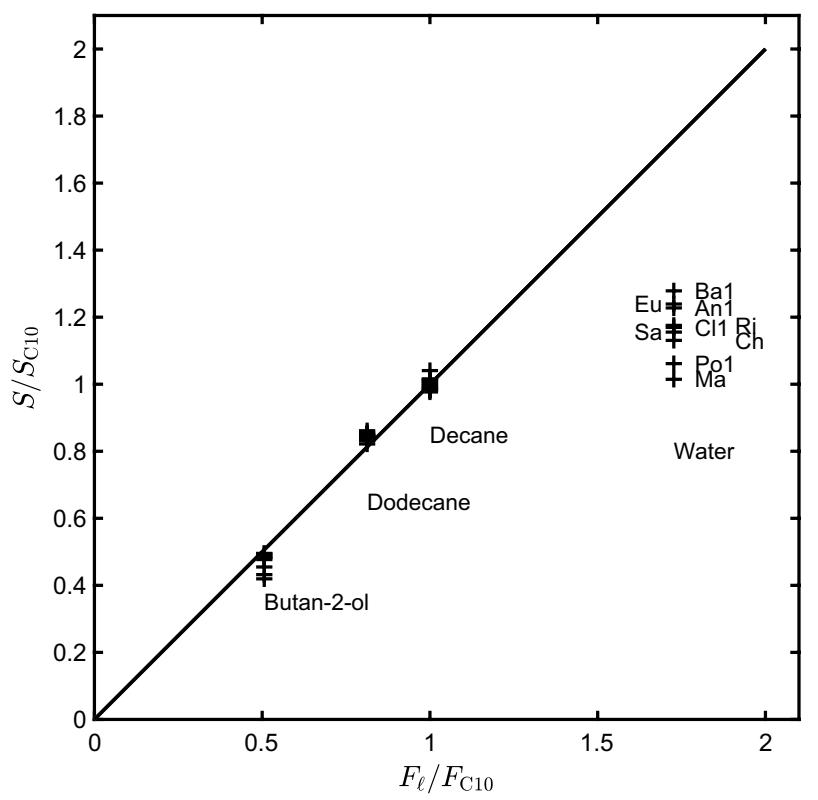

Fig. 2 Sorptivity and $F$-scaling, Series One: $S_{\ell} / S_{\mathrm{C} 10}$ vs $F_{\ell} / F_{\mathrm{C} 10}$, where $\mathrm{C} 10$ denotes $n$-decane as the reference liquid

this line, indicating partial wetting of all limestones by water. The spread in $S_{w} / S_{1}$ values corresponds to values of $\beta$ for water imbibition in the range of $0.35-0.55$. The water wetting coefficients for each limestone are given in Table 3, with the corresponding notional contact angles.

Series Two This comprises 63 individual imbibition tests. Since many of these lasted for two years or more, tests were necessarily carried out in parallel using 4-6 blocks of each type of limestone. Therefore, we use a somewhat different method to compare primary sorptivity data, since we now have to allow for some variability between individual blocks of the same stone. In addition, we do not have data on all liquids on all blocks, and therefore, we cannot select a single reference liquid. However, we see from the Series One data that nonaqueous liquids of low surface tension appear to completely wet these calcitic limestones. We therefore proceed as follows. For each block, we calculate for each liquid used a value for the intrinsic sorptivity $\mathbb{S}_{\ell}=S_{\ell} / F_{\ell}$. These values are similar for different nonaqueous liquids imbibed by each individual block of each stone, but without exception significantly lower for water. To display these results graphically (Fig. 3), we then calculate a normalised intrinsic sorptivity $\mathbb{S}_{\ell} / \overline{\mathbb{S}}_{n \ell}$, where $\overline{\mathbb{S}}_{n \ell}$ is the mean value of the intrinsic sorptivity for the nonaqueous liquids alone. This procedure provides a clear and direct way to show that the water imbibition is considerably slower than expected from a simple $F$-scaling. This confirms the findings of Series One tests. Again, we attribute this to partial wetting by water. Values of the water wetting coefficient for each test block for which we also have at least one imbibition dataset with an nonaqueous liquid are then calculated from $\left.\beta=\left[S_{w} /\left(F_{w} \overline{\mathbb{S}}_{n \ell}\right)\right]^{2}=\left[\mathbb{S}_{w} / \overline{\mathbb{S}}_{n \ell}\right)\right]^{2}$. These values are given in Table 3 . The range is 0.47-0.61, similar to that found in the Series One tests. For the English limestones, the Series One and Series Two values can be compared directly: in both cases, the order of decreasing wetting coefficient $\beta$ is $\mathrm{Ba}>\mathrm{An}>\mathrm{Cl}>\mathrm{Po}$, as shown in Fig. 4. 
Table 3 Estimated wetting coefficients for water imbibition into limestones

\begin{tabular}{ll}
\hline Type & Wetting coefficient $\beta$ \\
& Notional \\
& contact angle \\
& $\gamma\left[{ }^{\circ}\right]$ \\
\hline
\end{tabular}

Series One

$\begin{array}{lll}\text { Ancaster An1 } & 0.51 & 60 \\ \text { Bath Ba1 } & 0.55 & 57 \\ \text { Chauvigny Ch } & 0.43 & 65 \\ \text { Clipsham Cl1 } & 0.46 & 63 \\ \text { Euville Eu } & 0.52 & 59 \\ \text { Massangis Ma } & 0.36 & 70 \\ \text { Portland Po1 } & 0.38 & 68 \\ \text { Richemont Ri } & 0.46 & 62 \\ \text { Savonnières Sa } & 0.45 & 63 \\ \text { Series Two } & & \\ \text { Ancaster An2 } & 0.58 & 55 \\ \text { Bath Ba2 } & 0.61 & 52 \\ \text { Clipsham Cl2 } & 0.53 & 58 \\ \text { Portland Po2 } & 0.47 & 61\end{array}$

(1) Values rounded to two significant figures; (2) Series One, measured on a single block of each stone; Series Two, means of $n$ blocks:

$\mathrm{An} 2, \mathrm{Ba} 2 n=2 ; \mathrm{Cl} 2 n=3 ; \operatorname{Po} 2 n=5$

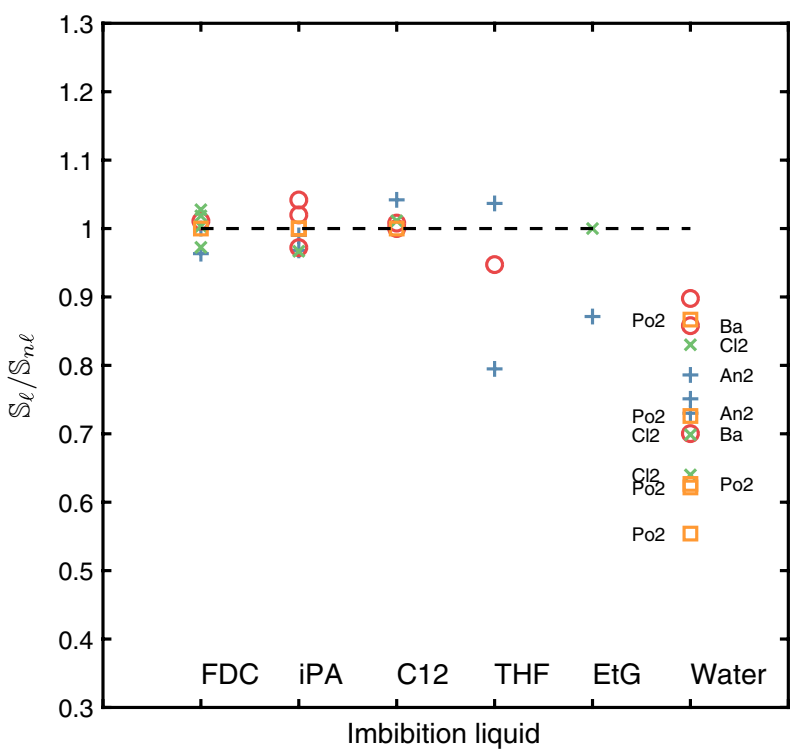

60

65

59

70

62

63

55

52

58

61
Fig. 3 Sorptivity and $F$-scaling, Series Two: $\mathbb{S}_{\ell} / \overline{\mathbb{S}}_{n \ell}$ for different imbibition liquids, denoted FDC perfluorodimethylcyclohexane, iPA propan-2-ol, C12 n-dodecane, THF tetrahydrofuran, EtG ethane-1,2-diol

Effect of surface tension In Fig. 3 the liquids $\ell$ are placed on the horizontal axis in order of increasing surface tension and the ordinate quantity $\mathbb{S}_{\ell} / \mathbb{S}_{n \ell}$ is an estimate of $\beta_{\ell}^{1 / 2}$, so that what is shown resembles an inverted Zisman plot. To emphasise this 
Fig. 4 Wetting coefficient of English limestones: Series One and Series Two compared

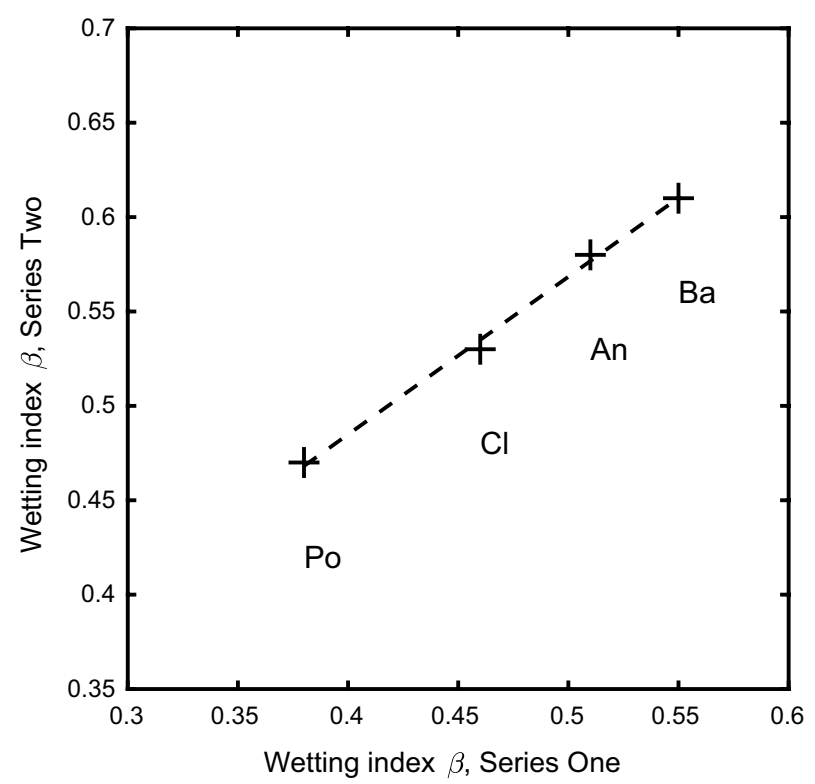

connection, the data of Fig. 3 are re-plotted as $\left(\mathbb{S}_{\ell} / \mathbb{S}_{n \ell}\right)^{2}$ versus $\sigma_{\ell}$ in Fig. 5, where results from Series One are also included.

Energetics of imbibition Spontaneous imbibition occurs only if the imbibition parameter $\square=\sigma_{\mathrm{s}}-\sigma_{\mathrm{s} \ell} \geq 0$, where $\sigma_{\mathrm{s}}$ is the surface tension of the dry solid, and $\sigma_{\mathrm{s} \ell}$ is the solid-liquid interfacial tension (de Gennes 1985). The wetting coefficient $\beta=\square / \sigma_{\ell}$, and partial wetting occurs when only when $0<\beta<1$. This requires that $\square<\sigma_{\ell}$, or in other words that $\sigma_{\mathrm{s}}<\sigma_{\mathrm{s} \ell}+\sigma_{\ell}$. The unmodified surface of an ionic inorganic mineral such as calcite is

Fig. 5 Estimated wetting coefficient $\beta_{\ell}=\left(\mathbb{S}_{\ell} / \mathbb{S}_{n \ell}\right)^{2}$ vs $\sigma_{\ell}$ for all limestones of Series One and Series Two with water and nonaqueous imbibition liquids

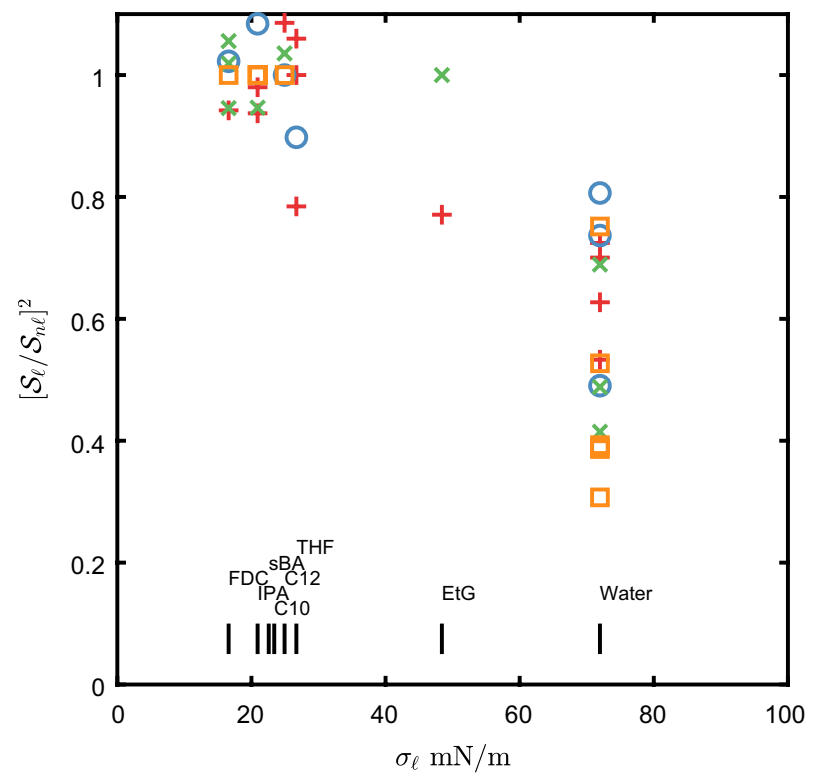


expected to have a large $\sigma_{\mathrm{s}}$, making this condition unlikely to be met. The fact that we observe partial wetting of water in limestones shows that the pore surface in contact with water is not unmodified, but is altered so as to greatly reduce $\sigma_{s}$.

Recent studies of the spreading of water droplets on freshly cleaved calcite surfaces show that contact angle increases from near zero to values $\sim 60-80^{\circ}$ over a few hours (Al Mahri et al. 2017; Wani et al. 2018). The aging is attributed to water vapour adsorption and micro-scale alteration of the surface by dissolution and reconstruction (see also Wojas et al. 2019). There are several earlier reports of high contact angles for water on calcite (Ethington 1990; Okayama et al. 1997). Taken together, these observations suggest that the chemisorption of water vapour alone greatly reduces the surface tension $\sigma_{\mathrm{s}}$ of calcite. Such adsorption must almost invariably occur in water imbibition. The influence of adlayers on the surface tension of solids was a topic discussed long ago by Zisman (Shafrin and Zisman 1967; Bernett and Zisman 1969).

There are in addition several lines of evidence, mainly from oilfield petrophysics (Thomas et al. 1993; Frye and Thomas 1993; Okhrimenko et al. 2014) and soil science (Carter and Mitterer 1978), that the calcite mineral surface has a strong tendency to chemisorb certain organic compounds, notably fatty acids such as oleic, stearic, fulvic and humic acids (Pacey 1989). Carboxylate groups bind to the calcite surface to form a hydrophobic surface layer containing outward-facing alkyl groups. In petrophysics, such organic adlayers are considered responsible for oil-wetting behaviour; and in laboratory studies, carbonate rocks are often pretreated with fatty acids to control wettability, as, for example, in Singh et al. (2016). Quarry limestones have been exposed to groundwater over their geological lifetime, and when extracted are invariably saturated with an aqueous "quarry sap" (Loughlin 1929).

In Taylor (1998), Taylor had suggested that the anomalous sorptivity of water that she had observed in several quarry limestones may be caused by the presence of adsorbed organic matter on the calcite surface, drawing on the earlier petrophysical studies of carbonate rocks. In Ioannou et al. (2004), there is some support for this explanation from tests in which the wetting coefficient of Lépine limestone increased towards (although did not reach) the value 1 after repeated treatments with hydrogen peroxide or repeated heating cycles. However, several efforts to detect the presence of organic adlayers analytically have been unsuccessful (V Pugsley, personal communication).

Examining the role of the Hirschwald coefficient There is a tacit assumption in the F-scaling of the sorptivity that the liquid content of the wetted region in a given porous material is the same for different imbibed liquids. If this is not the case, then we may expect that the effective permeability $K_{e}$ varies not only as $1 / \eta_{\ell}$ but also in some fashion with $\theta_{\ell}$. The Series Two tests were continued until primary imbibition was complete, so that for the four English limestones that were used $\theta_{\ell}$ can be estimated. Since the porosity $f$ is also known, it is convenient to express the results as the fractional Hirschwald coefficient $\mathrm{h}=\mathrm{H} / 100=\theta_{\ell} / f$. The quantity $h$ is the fraction of the pore space occupied by imbibed liquid at the end of primary imbibition, the remaining fraction $1-\mathrm{h}$ being occupied by trapped air. It should be noted that the "twotangent" construction, shown in Fig. $1 \mathrm{~b}$ and commonly used in the construction materials field (Hens 1976; Roels et al. 2004), is not well anchored theoretically. The slow changes in sample weight after primary imbibition reflect complex air-diffusion processes within the sample and do not strictly increase as $t^{1 / 2}$ (Hall and Hamilton 2018). The slope of the later-time regression line is therefore somewhat ill-defined. Nevertheless, in practice, no other method of analysis is available, and the results are sufficiently reproducible to be informative. Results from Series Two tests are shown in Fig. 6 and in Table 4. They provide no clear evidence of significant differences in $\mathrm{h}$ between water and the nonaqueous liquids. Only in the case of Portland stone 
Fig. 6 Fractional Hirschwald coefficient $h$ for Series Two limestones with different imbibition liquids

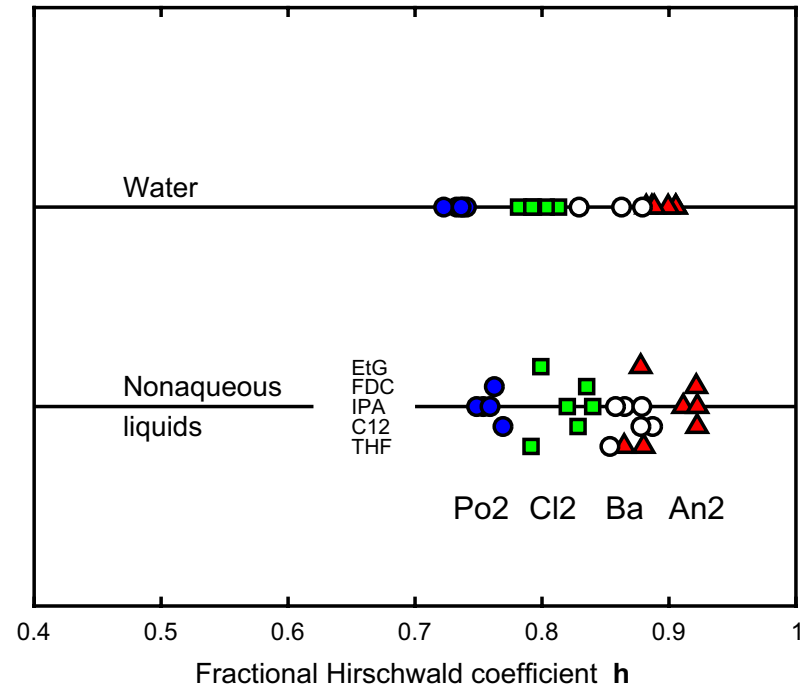

\begin{tabular}{lll}
\hline Type & Water & Nonaqueous liquids \\
\hline Ancaster An2 & $0.89 \pm 0.01$ & $0.91 \pm 0.02$ \\
Bath Ba2 & $0.86 \pm 0.03$ & $0.87 \pm 0.01$ \\
Clipsham C12 & $0.80 \pm 0.01$ & $0.82 \pm 0.02$ \\
Portland Po2 & $0.73 \pm 0.01$ & $0.76 \pm 0.01$ \\
\hline
\end{tabular}

Values are means of measurements on several blocks of each stone type; uncertainties are standard deviations
Table 4 Fractional Hirschwald coefficient $h$ estimated for Series Two limestones

do the mean values lie outside the standard-deviation uncertainties. The question whether a (small) contribution to the observed pattern of sorptivities may arise from differences in $\mathrm{h}$, and hence in $\theta_{\ell}$, is open for further investigation.

Earlier work The behaviour reported here is broadly in line with the few earlier related observations on quarry limestones. In Taylor (1998) and Taylor et al. (2000), wetting coefficients for water imbibition were obtained on five materials, including both a Portland $(f=0.19)$ and a Richemont $(f=0.26)$ stone. There is some overlap with the present study in materials used. In addition to water, six nonaqueous imbibition liquids were used: three hydrocarbons ( $n$-heptane, $n$-decane and $n$-dodecane) and three alcohols (methanol, ethanol and propan-2-ol). Tests were carried out over a wide range of temperatures, from -4 to $62{ }^{\circ} \mathrm{C}$. The wetting coefficients for the five limestones lay in the range $0.11-0.72$, Portland stone having $\beta=0.22$ and Richemont 0.33 , both lower than found here for similar materials. In (Ioannou et al. 2004), $\beta$ for Lépine limestone was found to be 0.35 . 


\section{Conclusions}

The failure of the $F$-scaling to describe the imbibition of water by quarry limestones must now be regarded as firmly established, since the present study extends the available data to cover more than a dozen limestones and a similar number of liquids. Our new results eliminate the possibility that low water sorptivity is caused by low values of the fractional Hirschwald coefficient (the residual nonwetting phase saturation), although there may be a small contribution from such an effect. The observed behaviour indicates that the calcite in these quarry limestones behaves as a Zisman low-energy surface, and that there is a Zisman critical surface tension $\sigma_{c}$, somewhere around $25-30 \mathrm{mN} / \mathrm{m}$.

In the absence of direct analytical evidence, the nature of the alteration of the pores surfaces in quarry limestones is an open question. There is no doubt that before they are extracted, these stones are in direct and perennial contact with percolating groundwater. This is a strong reason to expect that the pore surfaces have acquired adlayers of chemisorbed organic matter. It is also likely that the molecular composition of these adlayers may vary from location to location, and that this accounts for the variation of wetting coefficient from stone to stone. Whether such adlayers are purely chemical in nature or have (or may sometimes have) a biogenic character (Villa et al. 2015) is not clear.

Acknowledgements We thank the Royal Society for funding, and $\mathrm{CH}$ acknowledges the use of the Stapleford Laboratory.

\section{Compliance with Ethical Standards}

Conflict of interest The authors declare that they have no conflicts of interest.

Open Access This article is licensed under a Creative Commons Attribution 4.0 International License, which permits use, sharing, adaptation, distribution and reproduction in any medium or format, as long as you give appropriate credit to the original author(s) and the source, provide a link to the Creative Commons licence, and indicate if changes were made. The images or other third party material in this article are included in the article's Creative Commons licence, unless indicated otherwise in a credit line to the material. If material is not included in the article's Creative Commons licence and your intended use is not permitted by statutory regulation or exceeds the permitted use, you will need to obtain permission directly from the copyright holder. To view a copy of this licence, visit http://creativecommons.org/licenses/by/4.0/.

\section{References}

Al Mahri, M.A., Alshehhi, M., Olukan, T., Vargas, M.R., Molini, A., Alhassan, S., Chiesa, M.: Surface alteration of calcite: interpreting macroscopic observations by means of AFM. Phys. Chem. Chem. Phys. 19, 25634-25642 (2017)

Bernett, M.K., Zisman, W.A.: Effect of adsorbed water on wetting properties of borosilicate glass, quartz, and sapphire. J. Colloid Interface Sci. 29, 413-423 (1969)

Carmeliet, J., Hens, H., Roels, S., Adan, O., Brocken, H., Cerny, R., Pavlik, Z., Hall, C., Kumaran, K., Pel, L.: Determination of the liquid water diffusivity from transient moisture transfer experiments. J. Therm, Envel.Build. Sci. 27, 277-305 (2004)

Carter, P.W., Mitterer, R.M.: Amino acid composition of organic matter associated with carbonate and non-carbonate sediments. Geochim. Cosmochim. Acta 42, 1231-1238 (1978)

Chen, F., Yang, Z., Chen, Z., Hu, J., Chen, C., Cai, J.: Density, viscosity, speed of sound, excess property and bulk modulus of binary mixtures of $\gamma$-butyrolactone with acetonitrile, dimethyl carbonate, and tetrahydrofuran at temperatures (293.15 to 333.15)K. J. Mol. Liq. 209, 683-692 (2015)

de Gennes, P.-G.: Wetting: statics and dynamics. Rev. Mod. Phys. 57, 827-863 (1985) 
Eley, D.D., Pepper, D.C.: The dynamical determination of adhesion tension. Trans. Farad. Soc. 42, 697702 (1946)

Ethington, E.F.: Interfacial contact angle measurements of water, mercury, and 20 organic liquids on quartz, calcite, biotite, and Ca-montmorillonite substrates, US Geological survey open file report pp. 90-409 (1990)

Frye, G.C., Thomas, M.M.: Adsorption of organic compounds on carbonate minerals: 2. Extraction of carboxylic acids from recent and ancient carbonates. Chem. Geol. 109, 215-226 (1993)

Green, W.H., Ampt, G.A.: Studies on soil physics. J. Agric. Sci. 4, 1-24 (1911)

Gummerson, R., Hall, C., Hoff, W.: Water movement in porous building materials-II. Hydraulic suction and sorptivity of brick and other masonry materials. Build. Environ. 15, 101-108 (1980)

Gummerson, R., Hall, C., Hoff, W., Hawkes, R., Holland, G., Moore, W.: Unsaturated water flow within porous materials observed by NMR imaging. Nature 281, 56-57 (1979)

Hall, C.: Water movement in porous building materials - I. Unsaturated flow theory and its applications, Build. Environ. 12, 117-125 (1977)

Hall, C.: The water sorptivity of mortars and concretes: a review. Mag. Concrete Res. 41, 51-61 (1989)

Hall, C., Hamilton, A.: Porosity-density relations in stone and brick materials. Mater. Struct. 48, 1265-1271 (2015)

Hall, C., Hamilton, A.: Porosities of building limestones: using the solid density to assess data quality. Mater. Struct. 49, 3969-3979 (2016)

Hall, C., Hamilton, A.: Beyond the sorptivity: definition, measurement, and properties of the secondary sorptivity. J. Mater. Civil Eng. (ASCE) 30, 04018049 (2018)

Hall, C., Hoff, W.D.: Rising damp: capillary rise dynamics in walls. Proc. R. Soc. A 463, 1871-1884 (2007)

Hall, C., Hoff, W.D.: Water Transport in Brick, Stone and Concrete, 2nd edn. Taylor and Francis, London (2012)

Hall, C., Tse, K.M.: Water movement in porous building materials-VII. The sorptivity of mortars. Build. Environ. 21, 113-118 (1986)

Hens, H.: Die hygrischen Eigenschaften von Ziegel. In: Proceedings of the 4th International Brick Masonry Conference (1976)

Hirschwald, J.: Handbuch der bautechnischen Gesteinsprüfung. Bornträger, Berlin (1912)

Ioannou, I., Charalambous, C., Hall, C.: The temperature variation of the water sorptivity of construction materials. Mater. Struct. 50, 208 (2017)

Ioannou, I., Hoff, W.D., Hall, C.: On the role of organic adlayers in the anomalous water sorptivity of Lépine limestone. J. Colloid Interface Sci. 279, 228-234 (2004)

Klute, A.: A numerical method for solving the flow equation for water in unsaturated materials. Soil Sci. 73, 105-116 (1952)

Loughlin, G.F.: Indiana Oolitic limestone: Relation of its natural features to its commercial grading. Contrib. Econ. Geol. Part I Met. Nonmet. Except Fuels 811, 113-202 (1929)

Martín Contreras, S.: Densities and viscosities of binary mixtures of 1,4-dioxane with 1-propanol and 2-propanol at $\left(25,30,35\right.$, and 40) ${ }^{\circ}$ C. J. Chem. Eng. Data 46, 1149-1152 (2001)

Okayama, T., Keller, D.S., Luner, P.: The wetting of calcite surfaces. J. Adhes. 63, 231-252 (1997)

Okhrimenko, D.V., Dalby, K.N., Skovbjerg, L.L., Bovet, N., Christensen, J.H., Stipp, S.L.S.: The surface reactivity of chalk (biogenic calcite) with hydrophilic and hydrophobic functional groups. Geochim. Cosmochim. Acta 128, 212-224 (2014)

Pacey, N.R.: Organic matter in cretaceous chalks from Eastern England. Chem. Geol. 75, 191-208 (1989)

Philip, J.: The theory of infiltration: 1. The infiltration equation and its solution, Soil Sci. 83, 345-358 (1957a)

Philip, J.R.: The theory of infiltration: 4. Sorptivity and algebraic infiltration equations, Soil Sci. 84, 257$264(1957 b)$

Philip, J.R.: Theory of infiltration. Adv. Hydrosci. 5, 215-296 (1969)

Quijada-Maldonado, E., Meindersma, G.W., de Haan, A.B.: Viscosity and density data for the ternary system water (1)-ethanol (2)-ethylene glycol (3) between $298.15 \mathrm{~K}$ and $328.15 \mathrm{~K}$. J. Chem. Thermodyn. 57, 500-505 (2013)

Roels, S., Carmeliet, J., Hens, H., Adan, O., Brocken, H., Cerny, R., Pavlik, Z., Hall, C., Kumaran, K., Pel, L., Plagge, R.: Interlaboratory comparison of hygric properties of porous building materials. J. Therm. Envel. Build. Sci. 27, 307-325 (2004)

Rowlinson, J.S., Widom, B.: Molecular Theory of Capillarity. Clarendon Press, Oxford (1982)

Schmid, K., Geiger, S.: Universal scaling of spontaneous imbibition for water-wet systems. Water Resourc. Res. 48, W03507 (2012)

Schmid, K.S., Alyafei, N., Geiger, S., Blunt, M.J.: Analytical solutions for spontaneous imbibition: fractional-flow theory and experimental analysis. SPE J. 21, 2308-2316 (2016) 
Shafrin, E.G., Zisman, W.A.: Effect of adsorbed water on the spreading of organic liquids on soda-lime glass. J. Am. Ceram. Soc. 50, 478-484 (1967)

Singh, K., Bijeljic, B., Blunt, M.J.: Imaging of oil layers, curvature and contact angle in a mixed-wet and a water-wet carbonate rock. Water Resourc. Res. 52, 1716-1728 (2016)

Somorjai, G.A.: Surface chemistry, Preprint UCRL-20382. University of California, Berkeley, Lawrence Radiation Laboratory (1970)

Taylor, S.C.: A study of liquid transport properties of cement-based materials. UMIST, Manchester (1998). $\mathrm{PhD}$ thesis

Taylor, S.C., Hall, C., Hoff, W.D., Wilson, M.A.: Partial wetting in capillary liquid absorption by limestones. J. Colloid Interface Sci. 224, 351-357 (2000)

Thomas, M.M., Clouse, J.A., Longo, J.M.: Adsorption of organic compounds on carbonate minerals: 1. Model compounds and their influence on mineral wettability. Chem. Geol. 109, 201-213 (1993)

Villa, F., Vasanthakumar, A., Mitchell, R., Cappitelli, F.: RNA-based molecular survey of biodiversity of limestone tombstone microbiota in response to atmospheric sulphur pollution. Lett. Appl. Microbiol. 60, 92-102 (2015)

Wani, O.B., Lai, C.Y., Quadri, S.M.R., Chiesa, M., Alhassan, S.M.: Understanding the wettability of calcite $\left(\mathrm{CaCO}_{3}\right)$ using higher spatial resolution. Energy Fuels 32, 10344-10353 (2018)

Washburn, E.W.: The dynamics of capillary flow. Phys. Rev. 17, 273-283 (1921)

Wojas, N.A., Swerin, A., Wallqvist, V., Järn, M., Schoelkopf, J., Gane, P.A., Claesson, P.M.: Iceland spar calcite: humidity and time effects on surface properties and their reversibility. J. Colloid Interface Sci. 541, 42-55 (2019)

Yaws, C.L., Lan, L.X.D.: Viscosity of liquid-organic compounds. In: Yaws, C.L. (ed.) Transport Properties of Chemicals and Hydrocarbons, vol. 3, pp. 101-193. William Andrew, Norwich (2009)

Yaws, C.L., Pike, R.W.: Density of liquid-organic compounds. In: Yaws, C.L. (ed.) Thermophysical Properties of Chemicals and Hydrocarbons, vol. 3, pp. 106-197. William Andrew, Norwich (2009)

Yaws, C.L., Richmond, P.C.: Surface tension-organic compounds. In: Yaws, C.L. (ed.) Thermophysical Properties of Chemicals and Hydrocarbons, vol. 21, pp. 686-781. William Andrew, Norwich (2009)

Zinszner, B., Pellerin, F.M.: A Geoscientist's Guide to Petrophysics. Editions Technip, Paris (2007)

Publisher's Note Springer Nature remains neutral with regard to jurisdictional claims in published maps and institutional affiliations. 